\title{
Klub edukasi kesehatan anak "Superman" sebagai upaya mewujudkan Indonesia sehat 2025
}

\author{
Aditya Zairian*, Iskandar Zulkarnain, Muhammad Kurnia Caesar, Yogi Amorega, dan Fadly Mulia \\ Universitas Riau \\ * adityazairian1@gmail.com
}

\begin{abstract}
Abstrak. SDN 120 Pekanbaru adalah sekolah yang terletak di Jalan Pesisir Ujung RT 3/RW 9 Kecamatan Rumbai Pesisir, Kota Pekanbaru, Provinsi Riau. Setelah dilakukan survei, sekolah ini belum memiliki Usaha Kesehatan Sekolah (UKS) dan masih banyak siswa yang belum memiliki pengetahuan dan implementasi kesehatan yang baik. Untuk menyelesaikan masalah kesehatan disana, maka penulis memberikan solusi berupa klub edukasi kesehatan anak bernama SUPERMAN untuk dilaksanakan disekolah tersebut. SUPERMAN merupakan program dengan konsep baru yang dibuat untuk mengarahkan anak usia sekolah dasar menjadi lebih peduli dengan Perilaku Hidup Bersih dan Sehat (PHBS) dan gizi. Metode yang digunakan dalam pelaksanaan program SUPERMAN adalah melalui ceramah, pelatihan, pembimbingan, permainan, dan aplikasi langsung. Hasil yang dicapai saat ini yaitu telah terbentuk klub edukasi kesehatan anak SUPERMAN dengan kegiatan Semua Sehat!; Perbaiki lemak dulu; Enaknya di Ruangan; Roar di Outdoor; dan Mantap badanku, sehat tubuhku (dibuktikan dengan Surat Keterangan (SK) pembentukan klub, SK kepengurusan, dan buku panduan klub), buku status gizi anggota (terdapat 6 orang anak yang mengalami obesitas $(21 \%)$ ), terdapat lima buah poster dan brosur kesehatan, dan pendokumentasian kegiatan. Setelah dilaksanakannya pengabdian ini, terjadi peningkatan pengetahuan siswa sebesar $20 \%$.
\end{abstract}

Kata kunci: superman, klub edukasi, kesehatan anak

\begin{abstract}
SDN 120 Pekanbaru is a school located on Jalan Pesisir Ujung RT 3/RW 9 District of Rumbai Pesisir, Kota Pekanbaru, Riau Province. After the survey, this school did not have Usaha Kesehatan Sekolah (UKS) and there were still many students who did not yet have the knowledge and implementation of good health. To solve health problems, the authors provide a solution in the form of a children's health education club called SUPERMAN to be implemented in the school. SUPERMAN is a program with a new concept created to direct elementary school age children to be more concerned with Perilaku Hidup Bersih dan Sehat (PHBS) and the nutrition. The method used in the implementation program is through lectures, training, mentoring, games, and direct applications. The results achieved at this time are the SUPERMAN club has been formed with Semua Sehat; Perbaiki Lemak Dulu; Enaknya di Ruangan; Roar di Outdoor; and Mantap Badanku, Sehat Tubuhku (evidenced by the club's formation certificate, management decree, and club guidebook), members' nutritional status books (there are 6 obese children (21\%)), there are five posters and brochures, and the documentation. After this activity was carried out, there wqas an increase in studeny knowledge by $20 \%$.
\end{abstract}

Keywords: superman, education club, child health

To cite this article: Zairian, A., I. Zulkarnain, M. K. Caesar, Y. Amorega, \& F. Mulia. 2019. Klub Edukasi Kesehatan Anak "Superman" Sebagai Upaya Mewujudkan Indonesia Sehat 2025. Unri Conference Series: Community Engagement 1: 21-30. https://doi.org/10.31258/unricsce.1.21-30 


\section{PENDAHULUAN}

Kesehatan anak merupakan salah satu topik penting dalam bidang kesehatan. Derajat kesehatan anak mencerminkan derajat kesehatan bangsa karena anak sebagai generasi penerus bangsa memiliki kemampuan yang dapat dikembangkan dalam meneruskan pembangunan bangsa (Hidayat AA, 2009). Masalah kesehatan anak yang masih banyak terjadi adalah obesitas. Obesitas merupakan penyakit akibat akumulasi lemak yang berlebihan dalam tubuh akibat ketidakseimbangan antara asupan makanan yang lebih besar dibandingkan dengan energi yang digunakan oleh tubuh. Berdasarkan data World Health Organization (WHO) pada 2013, persentase obesitas anak di Indonesia merupakan yang tertinggi di ASEAN. Hampir 12\% anak Indonesia mengalami obesitas. Jika dirinci lagi, dari 17 juta anak yang mengalami obesitas di ASEAN, 7 jutanya berasal dari Indonesia. Riskesdas 2013 menggambarkan kondisi anak di Indonesia sebanyak 8 dari 100 anak Indonesia yang mengalami obesitas. Apabila peningkatan obesitas terus berlanjut dan tidak ditatalaksana dengan baik maka pada tahun 2025 tidak mustahil penduduk Indonesia akan menyandang gelar "Obesogenik" (Riskesdas, 2013). Obesitas anak menjadi masalah kesehatan yang serius bukan hanya karena keberlanjutannya menjadi obesitas dewasa, tetapi juga karena dampak negatif yang ditimbulkan terhadap kesehatan (Kemenkes, 2012). Banyaknya kejadian obesitas pada anak usia sekolah membuktikan bahwa sikap dan perilaku peserta didik di sekolah masih belum menunjukkan peningkatan yang baik dalam derajat kesehatannya bahkan semakin menurun daya hayat dan daya tangkalnya terhadap pengaruh buruk. Sebagian besar penyebabnya adalah kurangnya kesadaran orang tua atau masyarakat terhadap cara-cara penanggulangan perilaku tersebut (Sutriyanto, 2011).

Penanaman kesadaran perilaku sehat selalu menyangkut unsur sikap yang sudah terbentuk secara laten. Untuk itu jelas pembentukan jangka waktu yang lama, yaitu suatu proses yang membutuhkan tekad dan usaha yang sungguh-sungguh. Paling efektif dalam upaya menanamkan kesadaran berperilaku sehat adalah anak usia 7 sampai 12 tahun, karena secara psikologis anak pada usia tersebut sedang memulai membentuk sikap terhadap sesuatu, oleh karena itu penanaman berperilaku sehat hendaknya dimulai dari usia dini yaitu mulai tingkat pendidikan dasar. Untuk itu, dibutuhkan tekad dan usaha yang sungguh-sungguh serta solusi aplikatif dalam menghadapi permasalahan kesehatan anak saat ini (Ip et al., 2017). Oleh karena itu kesehatan anak menjadi salah satu fokus perhatian pemerintah untuk menciptakan Indonesia yang sehat dan terbebas dari penyakit, hal ini tercantum dalam rancangan pemerintah yakni Indonesia Sehat 2025.

Rencana pembangunan jangka panjang bidang kesehatan RI tahun 2005-2025 atau "Indonesia Sehat 2025" disebutkan bahwa perilaku masyarakat yang diharapkan dalam Indonesia Sehat 2025 adalah perilaku yang bersifat proaktif untuk memelihara dan meningkatkan kesehatan; mencegah risiko terjadinya penyakit; melindungi diri dari ancaman penyakit dan masalah kesehatan lainnya; sadar hukum; serta berpartisipasi aktif dalam gerakan kesehatan masyarakat, termasuk menyelenggarakan masyarakat sehat dan aman (Kim et al., 2013).

Untuk menjawab tantangan tersebut maka klub edukasi kesehatan anak SUPERMAN merupakan salah satu cara untuk mewujudkan Indonesia sehat pada tahun 2025. SUPERMAN merupakan program dengan konsep baru yang dibuat oleh penulis untuk mengarahkan anak usia sekolah dasar menjadi lebih peduli dengan gizi dan kesehatan. Perbedaan program ini dari program edukasi lainnya adalah adanya konsep from child to child. Melalui konsep from child to child, anak akan dilatih untuk memiliki jiwa kepemimpinan sejak dini. Dengan menumbuhkan jiwa kepemimpinan sejak dini, diharapkan mereka mampu menjadi contoh dan teladan bagi teman sebaya, keluarga, serta orang-orang terdekatnya untuk lebih peduli terhadap masalah kesehatan.

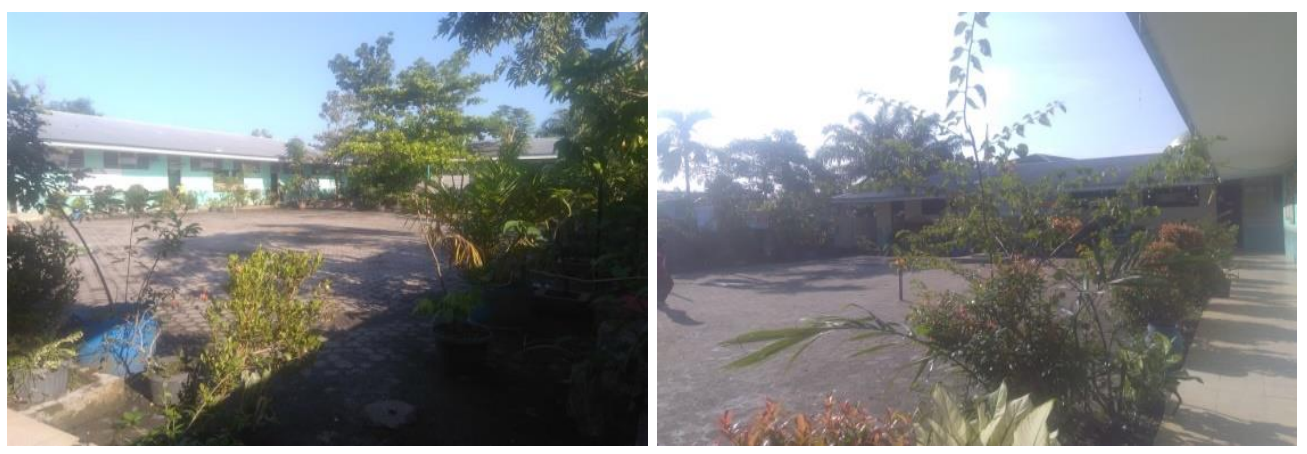

Gambar 1. SD Negeri 120 Pekanbaru 
Klub SUPERMAN dilaksanakan di Sekolah Dasar Negeri 120 Pekanbaru yang terletak di Jalan Pesisir Ujung RT 3/RW 9 Kecamatan Rumbai Pesisir, Kota Pekabaru, Provinsi Riau. Pemilihan sasaran edukasi di Sekolah Dasar Negeri 120 Pekanbaru, dikarenakan masih kurang sarana-prasarana serta edukasi tentang kesehatan anak di sekolah ini. Sekolah ini belum memiliki fasilitas usaha kegiatan sekolah (UKS) yang membuat kesehatan anak kurang diperhatikan. Rendahnya pengetahuan anak tentang status gizi dan obesitas, membuat perilaku hidup sehat siswa di sekolah ini tergolong buruk. Selain itu juga, sekolah ini merupakan ruang lingkup dari Kampung Pelita Medika I (KPM I) Fakultas Kedokteran Universitas Riau yang merupakan program unggulan dari fakultas ini. Diharapkan, tujuan dibentuknya kampung pelita medika yakni melaksanakan tri dharma perguruan tinggi dapat tercapai melalui klub SUPERMAN.

Tujuan dari pengabdian masyarakat ini adalah untuk mengedukasi anggota siswa SD Negeri 120 Pekanbaru tentang kesehatan anak dengan cara unik dan menarik. Selain itu, untuk membiasakan anak-anak berperilaku hidup bersih dan sehat dalam kehidupan sehari-hari. Luaran yang diharapkan dari program klub edukasi kesehatan anak SUPERMAN yaitu:

a. Pembentukan klub edukasi kesehatan anak di SD Negeri 120 Pekanbaru.

b. Penemuan dini kasus obesitas.

c. Poster serta brosur kesehatan sebagai media edukasi pencegahan penyakit.

d. Foto dan video yang meliputi dokumentasi kegiatan.

\section{Masalah}

Dari gambaran umum masyarakat yang telah dijelaskan sebelumnya, dapat diidentifikasi dan diberikan alternatif pemecahan masalah yang dapat dilihat pada Tabel 1 .

Tabel 1. Identifikasi dan Alternatif Pemecahan Masalah

\begin{tabular}{|c|c|c|}
\hline No & Identifikasi Masalah & Alternatif Pemecahan Masalah \\
\hline 1 & $\begin{array}{l}\text { SDN } 120 \text { Pekanbaru belum memiliki Usaha } \\
\text { Kegiatan Sekolah (UKS) }\end{array}$ & $\begin{array}{l}\text { Membuat klub edukasi kesehatan anak dengan } \\
\text { konsep yang menarik dan inovatif }\end{array}$ \\
\hline 2 & $\begin{array}{l}\text { Anak-anak yang belum tahu cara mencuci } \\
\text { tangan }\end{array}$ & $\begin{array}{l}\text { Mengajarkan dan mempraktikkkan cara mencuci } \\
\text { tangan yang dianjurkan oleh World Health } \\
\text { Organization (WHO) }\end{array}$ \\
\hline 3 & $\begin{array}{l}\text { Lingkungan sekolah yang kotor dan banyak } \\
\text { sampah }\end{array}$ & $\begin{array}{l}\text { Mengajak anak-anak untuk gotong royong bersama } \\
\text { membersihkan lingkungan sekolah }\end{array}$ \\
\hline 4 & Anak-anak kurang suka berolahraga & $\begin{array}{l}\text { Mengajak anak-anak untuk senam bersama dan } \\
\text { olahraga ringan }\end{array}$ \\
\hline 5 & $\begin{array}{l}\text { Kurangnya pengetahuan anak-anak tentang } \\
\text { gizi dan masalah kesehatan }\end{array}$ & $\begin{array}{l}\text { a. Memberikan informasi seputar dan kesehatan } \\
\text { anak serta pembagian buku cerita pendek berbasis } \\
\text { kesehatan berjudul Obat Kenanganku } \\
\text { b. Melakukan permainan UNGGAS (Ular Tangga } \\
\text { SUPERMAN) untuk meningkatkan pemahaman } \\
\text { dan pengetahuan anak terhadap materi kesehatan } \\
\text { yang telah diberikan sebelumnya }\end{array}$ \\
\hline 6 & $\begin{array}{l}\text { Anak-anak belum sepenuhnya } \\
\text { mengimplementasikan pengetahuan tentang } \\
\text { kesehatan dalam kehidupan sehari-hari }\end{array}$ & $\begin{array}{l}\text { a. Mengimplementasikan dan mengevaluasi } \\
\text { pengetahuan yang dimiliki oleh anak-anak } \\
\text { melalui permainan, makan bersama, dan } \\
\text { pemberian buah-buahan } \\
\text { b. Memonitoring perilaku hidup sehat melalui kartu } \\
\text { anggota klub }\end{array}$ \\
\hline 7 & Anak-anak belum mengetahui status gizinya & $\begin{array}{l}\text { Mengukur tinggi dan berat badan, serta melakukan } \\
\text { perhitungan status gizi berdasarkan kriteria CDC } \\
2000\end{array}$ \\
\hline
\end{tabular}




\begin{tabular}{lll}
\hline No & \multicolumn{1}{c}{ Identifikasi Masalah } & \multicolumn{1}{c}{ Alternatif Pemecahan Masalah } \\
\hline 8 & $\begin{array}{l}\text { Belum ada data tentang kasus obesitas pada } \\
\text { siswa SDN 120 Pekanbaru }\end{array}$ & $\begin{array}{l}\text { Melalui perhitungan status gizi, akan dipilih siswa } \\
\text { yang memiliki status gizi obesitas dan akan } \\
\text { dilakukan edukasi }\end{array}$ \\
\hline
\end{tabular}

\section{METODE PENERAPAN}

SUPERMAN merupakan program dengan konsep baru yang lebih mengarahkan anak usia sekolah dasar menjadi lebih peduli dengan gizi dan kesehatan. Program ini dibangun menggunakan konsep 'from child to child' sebagai porosnya berada pada pembinaan anak sekolah dasar. Melalui konsep 'from child to child', anak akan dilatih untuk memiliki jiwa kepemimpinan sejak dini. Konsep yang dibangun bersifat menyeluruh karena melihat berbagai faktor yang ikut mempengaruhi gizi dan kesehatan.

Kata "SUPERMAN" merupakan singkatan dari lima program yang dilaksanakan pada klub ini meliputi: Semua sehat!; Perbaiki lemak dulu; Enaknya di ruangan; Roar di outdoor; dan Mantap badanku, sehat tubuhku. Kelima program tersebut saling berkaitan satu sama lain yang terbina secara menyeluruh serta mampu memupuk jiwa kepemimpinan anak sejak dini.

Pada saat pelaksanaan program digunakan metode yang interaktif dan menarik. Metode yang digunakan dalam pelaksanaan program SUPERMAN adalah melalui ceramah, pelatihan, pembimbingan, permainan, dan aplikasi langsung. Pengenalan terhadap kesehatan anak dikenalkan melalui proses ceramah. Ceramah yang dilaksanakan bersifat interaktif dan berjalan komunikasi dua arah. Pelatihan dan pembimbingan dilakukan pada siswa yang sudah tergabung dalam SUPERMAN. Pelatihan dan pembimbingan ini menggunakan metode permainan dan aplikasi langsung. Proses pelaksanaannya, guru juga dilibatkan dalam memberikan arahan kepada siswa.

Program SUPERMAN dilaksanakan selama tiga bulan dari April-Juni 2019 di SD Negeri 120 Pekanbaru, Kelurahan Meranti Pandak, Kecamatan Rumbai Pesisir, Kota Pekanbaru, Provinsi Riau. Sebelum pelaksanaan kegiatan, terlebih dahulu dilaksanakan sosialisasi ke pihak sekolah maupun lingkungan sekitar mengenai maksud dan tujuan dilaksanakan program SUPERMAN. Selanjutnya, dilakukan perekruitmen anggota klub. Perekruitan anggota klub dilakukan melalui seleksi yang dipilih melalui saran dan rekomendasi dari guru. Anggota klub SUPERMAN dibatasi sebanyak 30 orang agar kegiatan yang dilaksanakan dapat lebih efisien dan terarah. Setiap anggota klub ini akan memiliki sebuah pin sebagai tanda keanggotaan di klub. Pin ini selain berfungsi sebagai penanda anggota klub juga digunakan sebagai salah satu strategi untuk meningkatkan rasa memiliki terhadap klub. Setelah anggota direkrut, dilakukan pre test untuk mengetahui tingkat pengetahuan siswa tentang kesehatan sebelum dilakukan program SUPERMAN.

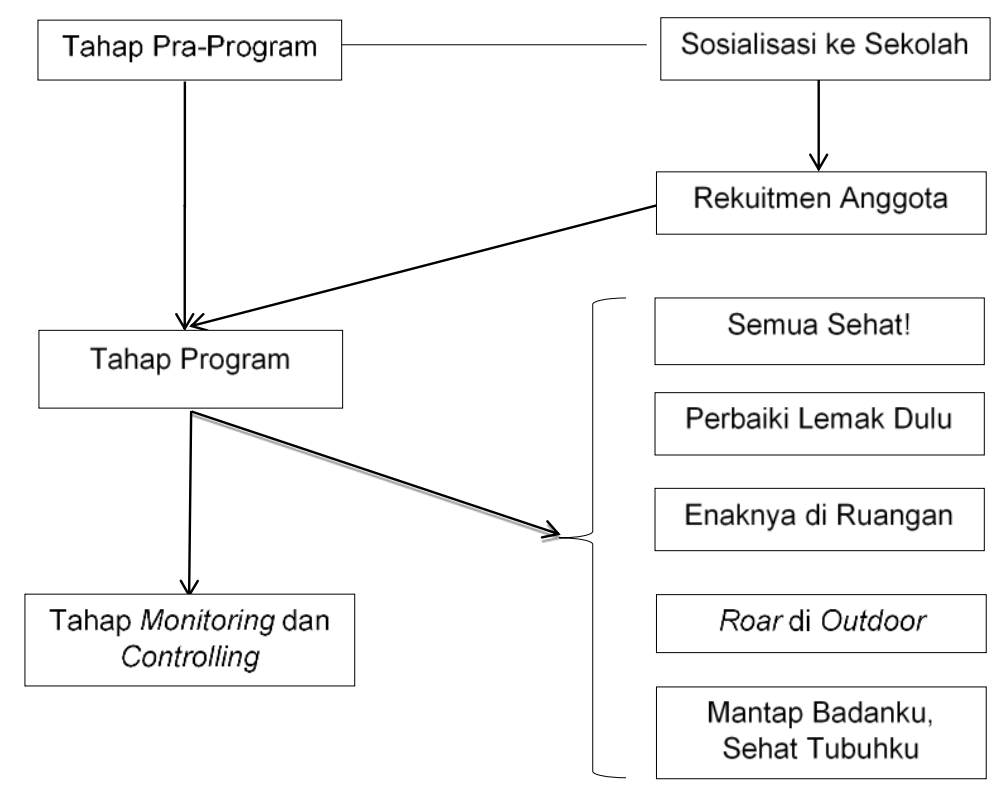

Gambar 2. Tahapan dan Instrumen Pelaksanaan SUPERMAN 


\section{Tahap Pelaksanaan Program}

a. Semua Sehat!

Pada program ini, diajarkan pola hidup sehat pada anak. Pada program ini, dilakukan beberapa hal:

1. Mencuci tangan, tentang enam langkah cuci tangan yang dianjurkan oleh World Health Organization (WHO).

2. Membuang sampah pada tempatnya, bertujuan untuk menciptakan lingkungan sehat dan bersih sehingga sarang penyakit dapat dibasmi di lingkungan sekolah. Selain itu, aktivitas fisik ringan dapat dilakukan dengan kegiatan ini yang secara tidak langsung, anak-anak akan berolahraga dengan memungut dan membuang sampah.

b. Perbaiki Lemak Dulu

Dilaksanakan senam bersama siswa-siswi sekolah, dilanjutkan dengan melakukan beberapa kegiatan olahraga ringan. Senam dipandu oleh mahasiswa kedokteran yang sudah dilatih dan menggunakan gerakan ringan serta mudah ditiru oleh anak-anak. Kegiatan olahraga lainnya seperti sepak bola, lari, dan lainnya dilakukan setelah senam ini.

c. Enaknya di Ruangan

Dilaksanakan di dalam kelas dengan metode ceramah oleh mahasiswa untuk memberikan edukasi tentang kesehatan yang meliputi: bahaya jika kurang aktivitas, mengkonsumsi makanan berlemak dan manis, pentingnya pola gizi seimbang, dan lainnya. Agar anak lebih memahami materi, maka dalam pelaksanaannya akan diberikan tidak hanya dalam bentuk ceramah tetapi juga melalui gambar, video, dan permainan. Selain itu anak-anak juga dilatih dan dilibatkan untuk bisa berbicara di depan kelas dan menyampaikan promosi kesehatan terhadap teman-temannya. Pada kegiatan ini, anak-anak dan pihak sekolah juga akan dibagikan buku Obat Kenanganku (Obesitas Itu Berat, Kamu Nggak Akan Kuat) yang telah ditulis oleh penulis sebelumnya untuk memberikan edukasi tentang obesitas melalui cerita pendek yang mudah dimengerti oleh anak-anak.

d. Roar di Outdoor

Dilaksanakan di luar kelas melalui permainan, yang menjadi tujuan dalam permainan ini adalah agar anakanak mengingat kembali materi yang telah disampaikan sebelumnya. Permainan dipandu oleh mahasiswa kedokteran dengan bermain UNGGAS (Ular Tangga SUPERMAN). Setelah permainan berakhir, anggota klub yang telah diminta membawa makanan sebelumnya akan dikumpulkan secara bersama untuk makan dengan teman-temannya. Makanan ini harus mengandung gizi seimbang dan diharapkan menjadi kebiasaan siswa-siswi agar tidak selalu jajan di luar. Kegiatan ini ditutup dengan pembagian dan makan snack buahbuahan yang telah pengurus beli sebelumnya.

e. Mantap Badanku, Sehat Tubuhku

Dalam program ini, diberikan informasi tentang obesitas yang dilanjutkan dengan pengukuran tinggi badan dan berat badan untuk mengukur tingkat obesitas. Kemudian, dihitung seberapa banyak anak yang memiliki indeks massa tubuh (IMT) kurus, normal, gemuk, dan obesitas melalui grafik IMT/U standar CDC 2000. Dari hasil tersebut, akan tampak persentase IMT di sekolah tersebut sehingga nantinya dapat dilakukan edukasi lebih lanjut.

Selanjutnya, controlling dan monitoring akan dilakukan setiap satu bulan sekali guna melihat efektifitas dan perkembangan pencapaian program. Setelah pelaksanaan program, dilaksanakan post test untuk menilai seberapa besar peningkatan pengetahuan anak setelah dilaksanakan program ini. Apabila terjadi peningkatan maka program ini dikatakan berhasil dan apabila tidak, maka program ini akan dievaluasi dan dicari solusi dari permasalahan tersebut.

Setelah semua program dijalankan, 30 murid yang menjadi anggota SUPERMAN akan menjadi kader untuk kegiatan selanjutnya. Dibantu dengan guru dan orang tua, program ini akan terus berlanjut. Jika perlu, program ini dapat menjadi kegiatan ekstrakulikuler sekolah yang berfokus pada bidang kesehatan. Setiap dua bulan sekali, mahasiswa akan mengunjungi sekolah tersebut dan mengevaluasi program. Apabila terdapat hal baru, maka dapat dimasukkan ke dalam program SUPERMAN sehingga tidak monoton dan membuat sesuatu yang baru.

Pengumpulan data akan dilakukan secara dua tahap, yakni sebelum dan sesudah pelaksanaan program. Pengumpulan akan dilakukan melalui kertas kuesioner berisi 10 pertanyaan pilihan ganda tentang pengetahun dasar kesehatan anak. Kuesioner tersebut akan diberikan kepada 30 anggota klub untuk menilai sejauh mana kemajuan siswa sebelum dan sesudah pelaksanaan program. Setelah didapatkan hasil, data tersebut akan diolah dan interpretasikan dalam bentuk tabel dan grafik untuk menilai ada atau tidaknya peningkatan pada 
pengetahuan siswa. Apabila terjadi peningkatan, maka program SUPERMAN dinyatakan berhasil dan apabila tidak, program SUPERMAN akan dievaluasi untuk diperbaiki. Tabel dan grafik tersebut akan dianalisis secara deskriptif untuk dianalisis sejauh mana keberhasilan program yang telah dilaksanakan.

\section{HASIL DAN KETERCAPAIAN SASARAN}

\section{Hasil yang Dicapai}

\section{Terbentuknya Klub Edukasi Kesehatan Anak}

Berdasarkan kegiatan pengabdian di SD Negeri 120 Pekanbaru, telah terbentuk klub edukasi kesehatan anak bernama SUPERMAN yang resmi berdiri pada tanggal 6 April 2019. Klub ini berjumlah 30 orang yang berasal dari siswa kelas 3, 4, dan 5. Ada lima kegiatan yang telah dilaksanakan selama empat minggu yang meliputi: Semua Sehat; Perbaiki Lemak Dulu; Enaknya di Ruangan; Roar di Outdoor; dan Mantap Badanku Sehat Tubuhku.

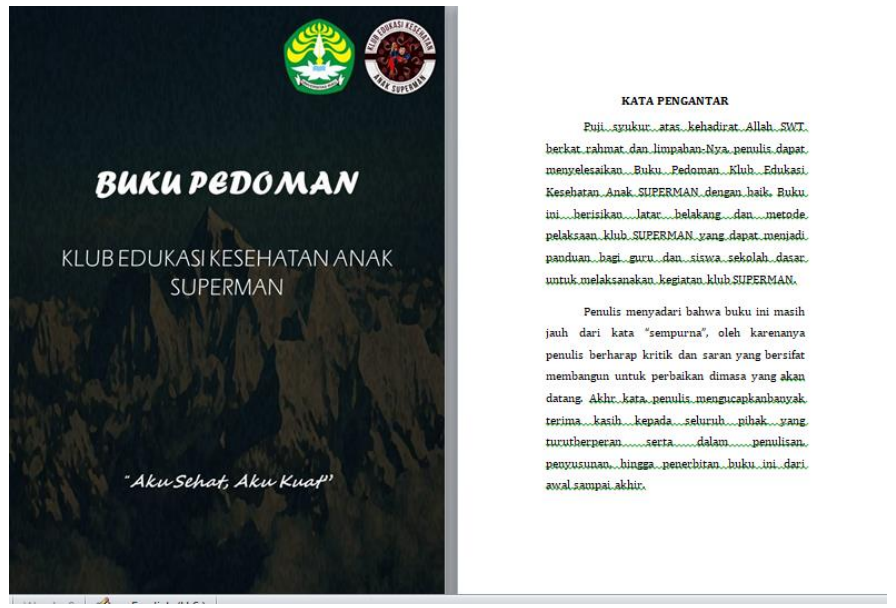

Gambar 3. Buku Pedoman Klub SUPERMAN

Untuk mengevaluasi kegiatan, setiap anggota diberikan dua buah kartu, yaitu kartu anggota klub dan kartu anak sehat. Kartu anggota klub diisi oleh pengurus SUPERMAN yang memuat nama dan waktu kegiatan, sedangkan kartu anak sehat diisi oleh masing-masing anggota selama satu minggu untuk mengevaluasi apakah anggota melaksanakan kegiatan harian ketika di rumah atau tidak. Dengan adanya kartu ini, diharapkan anak mampu menerapkan materi kesehatan yang telah diberikan sebelumnya dalam kehidupan sehari-hari.

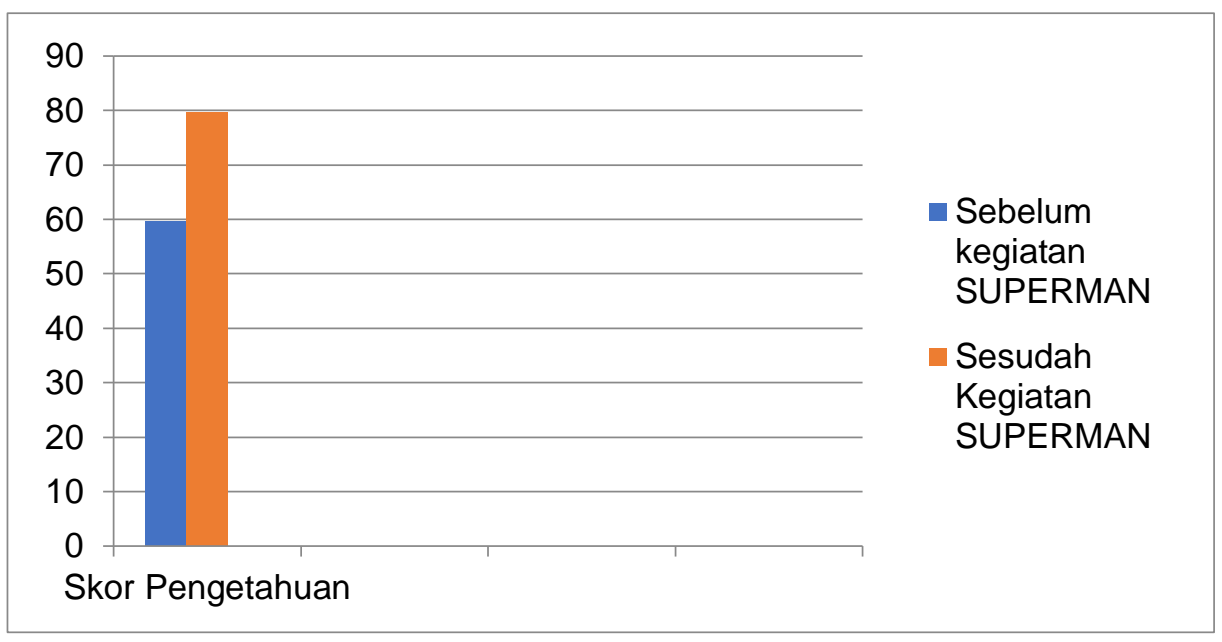

Gambar 4. Perbandingan Rata-Rata Skor Pengetahuan Sebelum dan Sesudah Kegiatan SUPERMAN

Setelah klub dibentuk, dikeluarkan surat keterangan dari SDN 120 tentang pembentukan klub edukasi kesehatan anak SUPERMAN dan struktur kepengurusan Untuk keberlanjutan program, telah dibuat buku pedoman klub SUPERMAN agar program ini dapat berjalan untuk ke depannya.

Sebelum dan sesudah dilaksanakan kegiatan SUPERMAN, dilakukan tes sebanyak 10 soal obyektif untuk menilai pengetahuan anggota klub. Berdasarkan pengujian statistik menggunakan aplikasi pengolah data, 
didapat bahwa rata-rata skor pengetahuan anggota klub sebelum dilaksanakan kegiatan SUPERMAN adalah 59,67 dan rata-rata skor pengetahuan sesudah dilaksanakan kegiatan adalah 79,67 (Gambar 4).

Dari hasil analisis data menggunakan uji t berpasangan, nilai $p$ value adalah 0,001 . Standar eror dalam analisis ini adalah 5\% yang berarti ada perbedaan yang signifikan skor pengetahuan anggota klub sebelum dan sesudah kegiatan SUPERMAN (Tabel 1).

Tabel 1. Distribusi Rata-Rata Skor Pengetahuan Sebelum dan Sesudah Kegiatan SUPERMAN di SD Negeri 120 Pekanbaru tahun 2019

\begin{tabular}{lcccccc}
\hline Skor Pengetahuan & Mean & Mean diff & SD & P value & N & 95\% CI \\
\hline Sebelum & 59,67 & -20 & 23,193 & 0,001 & 30 & $-28,661-(-11,339)$ \\
Sesudah & 79,67 & & & & & \\
\hline
\end{tabular}

Berdasarkan Gambar 4 dan Tabel 2, dapat disimpulkan bahwa pengetahuan anggota klub meningkat setelah dilaksanakannya kegiatan SUPERMAN.

\section{Penemuan Dini Kasus Obesitas}

Berdasarkan pengujian statistik menggunakan aplikasi pengolah data, rata-rata tinggi badan anggota klub SUPERMAN adalah 132,97 cm, sedangkan rata-rata berat badan anggota klub SUPERMAN adalah 30,67 kg (Tabel 2).

Tabel 2. Rata-Rata Tinggi dan Berat Badan Anggota Klub SUPERMAN

\begin{tabular}{lcccc}
\hline & N & Minimum & Maksimum & Rata-Rata \\
\hline Tinggi Badan & 30 & 117 & 156,7 & 132,97 \\
Berat Badan & & 19 & 68 & 30.67 \\
\hline
\end{tabular}

Berdasarkan pengukuran tinggi dan berat badan pada anggota klub, terdapat 6 anak yang memiliki status gizi obesitas. Untuk status gizi overweight, normal, dan malnutrisi kurang, masing-masing adalah 2, 20, dan 2 (Gambar 5).

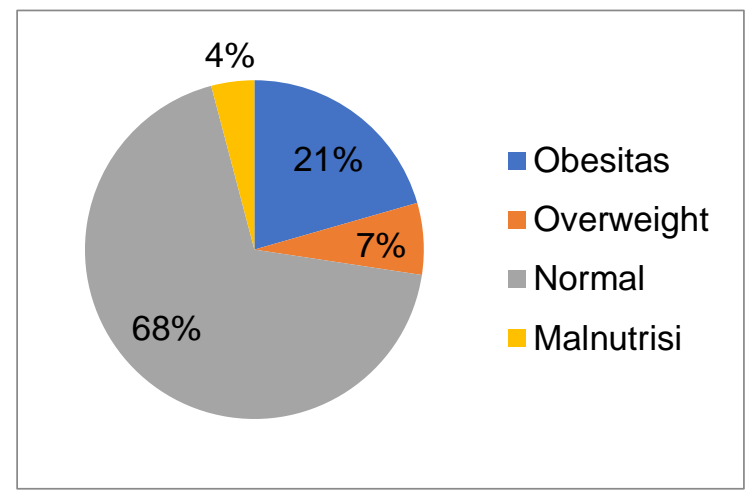

Gambar 5. Diagram Status Gizi Anggota Klub SUPERMAN

Untuk mengarsipkan kegiatan dan sebagai panduan pengukuran tinggi dan berat badan pada kegiatan SUPERMAN, buku status gizi kesehatan klub SUPERMAN juga telah dibuat. Buku ini berisikan tentang topik obesitas dan status gizi pada anggota klub SUPERMAN. Buku ini akan menjadi panduan bagi kader untuk melanjutkan kegiatan serupa untuk ke depannya. 


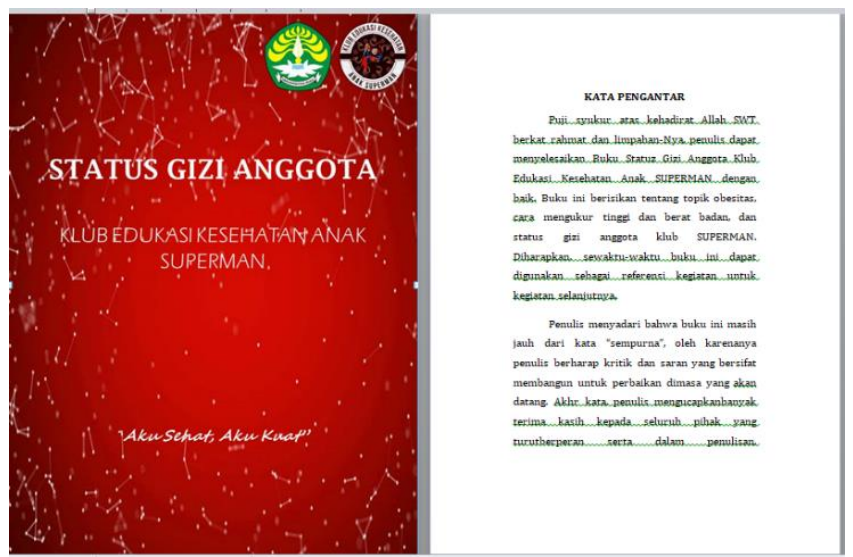

Gambar 6. Buku Status Gizi Anggota Klub SUPERMAN

\section{Poster dan Brosur Kesehatan}

Dalam menjalankan kegiatan SUPERMAN, telah dibuat lima buah poster dengan topik yang berbeda yaitu gizi seimbang, imunisasi, pentingnya olahraga, gosok gigi, dan obesitas. Pemilihan topik ini didasari atas permasalahan ataupun isu kesehatan yang melekat pada anak-anak. Poster ini ditampilkan sebagai media edukasi saat penyampaian materi kesehatan baik di dalam maupun di luar ruangan.
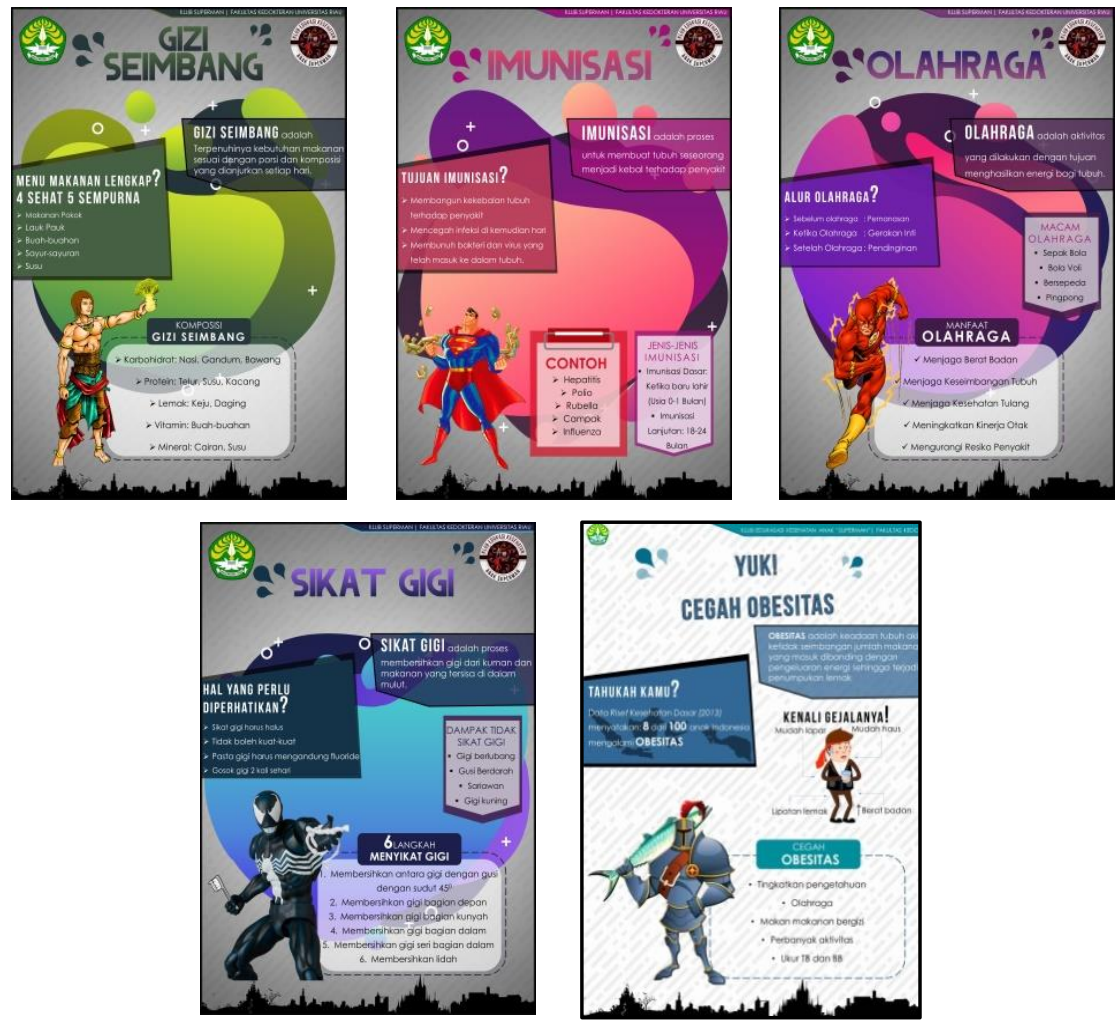

Gambar 7. Contoh Poster dan Brosur Kesehatan Klub SUPERMAN

\section{Dokumentasi Kegiatan}

Setiap kegiatan SUPERMAN telah didokumentasikan dalam bentuk gambar dan video. Dokumentasi ini disimpan apabila dipergunakan sewaktu-waktu, misalnya untuk laporan pertanggungjawaban. Foto dan video tersebut juga dimasukkan ke akun sosial media klub SUPERMAN yaitu Instagram (@klub.superman) dan YouTube (Klub SUPERMAN). Selain itu, kegiatan SUPERMAN juga telah dimuat dalam surat kabar yaitu Riau Terkini, Riau Green, Kompas Riau, dan Salisma. Penyebarluasan informasi secara digital maupun cetak ini bertujuan agar masyarakat mengetahui kegiatan SUPERMAN yang telah dilaksanakan di SDN 120 Pekanbaru. 

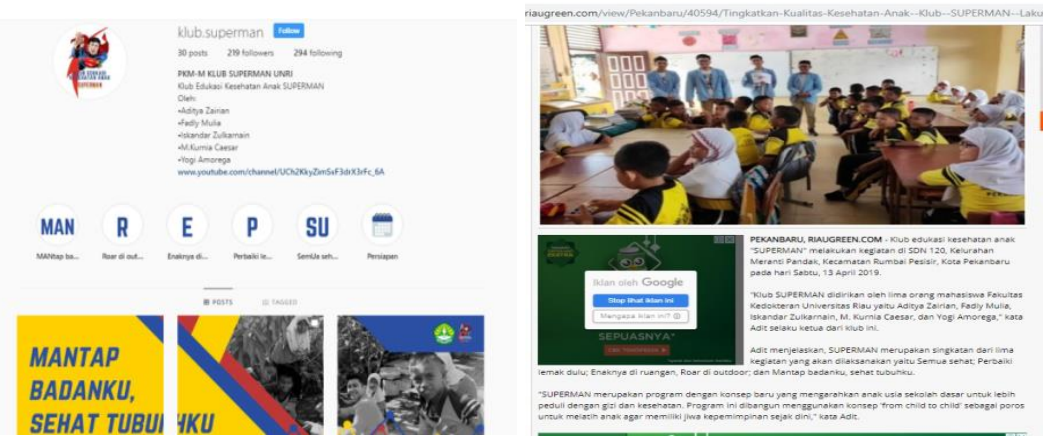

Gambar 7. Akun Sosial Media dan Pemuatan dalam Media Online

\section{Keunggulan dan Kelemahan}

Keunggulan dari klub edukasi kesehatan anak "SUPERMAN" adalah dapat dijadikan sebagai alternatif bagi sekolah dasar yang belum memiliki Usaha Kegiatan Sekolah (UKS), Materi kesehatan yang up to date sesuai dengan Kemenkes RI, kegiatan yang fleksibel dan tidak kaku, melakukan pemeriksaan kesehatan (TB dan BB) sekaligus melakukan interpretasi gizi dan dilakukan edukasi secara face to face, memiliki permainan kesehatan bernama UNGGAS (Ular Tangga SUPERMAN) raksasa, dan mengedukasi melalui buku cerita pendek berbasis kesehatan "Obat Kenanganku" (Obesitas Itu Berat, Kamu Nggak Akan Kuat) yang telah terdaftar ISBN dan mendapat HAKI. Kelemahan dari pengabdian ini adalah membutuhkan waktu yang lama, tantangan dalam mengatur anak-anak yang merupakan anggota klub, dan membutuhkan kader yang mengerti tentang kesehatan anak.

\section{Tingkat Kesulitan dan Peluang}

Dalam pengabdian ini, tingkat kesulitan pengerjaannya adalah $40 \%$ dimana penulis harus memami materi kesehatan anak, interpretasi status gizi, dan mengatur anak-anak untuk tetap tenang selama kegiatan berlangsung.

Klub SUPERMAN berdiri pada tanggal 8 April 2019 di SDN 120 Pekanbaru yang dibuktikan dengan keluarnya Surat Keterangan (SK) tentang pembentukan klub dan pengurusnya. Adanya SK membuat klub SUPERMAN secara resmi telah ada di sekolah ini, sehingga kegiatan SUPERMAN tetap berjalan untuk ke depannya. Selain itu, telah dibentuk kader klub dengan guru dan 30 siswa sebagai penggeraknya. Dengan adanya kader, diharapkan mereka dapat mengaplikasikan kegiatan SUPERMAN untuk ke depannya.

\section{Ketercapaian Target Luaran}

Ketercapaian target luaran selama menyelenggarakan pengabdian di SD Negeri 120 Pekanbaru sebesar 100\%, dengan rincian sebagai berikut:

Tabel 3. Ketercapaian Target Luaran

\begin{tabular}{|c|c|c|c|}
\hline \multirow{2}{*}{ No } & \multirow{2}{*}{ Target } & \multicolumn{2}{|c|}{ Ketercapaian Target } \\
\hline & & Terlaksana $(\%)$ & Belum Terlaksana $(\%)$ \\
\hline \multirow[t]{11}{*}{1} & Terbentuknya klub edukasi kesehatan anak & & \\
\hline & - $\quad$ Kegiatan: & & \\
\hline & a. Semua Sehat! & & \\
\hline & b. Perbaiki Lemak Dulu & & \\
\hline & c. Enaknya di Ruangan & & \\
\hline & d. Roar di Outdoor & & \\
\hline & e. Mantap Badanku, Sehat & & \\
\hline & Tubuhku & & \\
\hline & SK Pembentukan klub SUPERMAN & & \\
\hline & SK Kepengurusan klub SUPERMAN & 100 & - \\
\hline & - $\quad$ Buku pedoman klub SUPERMAN & & \\
\hline 2 & $\begin{array}{l}\text { Penemuan dini kasus obesitas } \\
\text { - Data status gizi anggota }\end{array}$ & 100 & - \\
\hline
\end{tabular}




\begin{tabular}{|c|c|c|c|}
\hline \multirow{2}{*}{ No } & \multirow{2}{*}{ Target } & \multicolumn{2}{|c|}{ Ketercapaian Target } \\
\hline & & Terlaksana $(\%)$ & Belum Terlaksana (\%) \\
\hline & $\begin{array}{l}\text { - Buku status gizi anggota klub } \\
\text { SUPERMAN }\end{array}$ & & \\
\hline 3 & $\begin{array}{l}\text { Poster dan brosur kesehatan sebagai media } \\
\text { edukasi pencegahan penyakit }\end{array}$ & 100 & - \\
\hline 4 & $\begin{array}{l}\text { Dokumentasi Kegiatan } \\
-\quad \text { Akun media sosial } \\
-\quad \text { Surat kabar }\end{array}$ & 100 & - \\
\hline & Tingkat Pencapaian & 100 & - \\
\hline
\end{tabular}

\section{KESIMPULAN}

Klub edukasi kesehatan anak SUPERMAN telah didirikan di SD Negeri 120 Pekanbaru. Pendirian klub ini didasari atas belum terbentuknya Usaha Kegiatan Sekolah (UKS) dan rendahnya pengetahuan serta perilaku hidup bersih dan sehat di sekolah ini. Berdirinya klub ini ditandai dengan keluarnya Surat Keterangan (SK) tentang pembentukan klub dan pengurusnya. Untuk keberlanjutan program, telah dibuat buku pedoman klub SUPERMAN dan buku status gizi anggota klub sehingga dapat dipakai untuk ke depannya. Berdasarkan hasil pengabdian, sebanyak $21 \%$ anggota mengalami obesitas dan telah diberikan edukasi untuk mengurangi berat badan. Setiap kegiatan SUPERMAN, telah dimasukkan ke dalam akun media klub dan media online agar masyarakat luas mengetahui kegiatan ini.

Untuk ke depannya, diharapkan kegiatan klub SUPERMAN dapat terus berlanjut dan menghadirkan kegiatan baru. Selain itu, klub ini dapat diduplikasikan dan diterapkan di sekolah-sekolah lain yang masih memiliki masalah kesehatan anak.

\section{UCAPAN TERIMA KASIH}

Terima kasih kepada Kementerian Riset, Teknologi, dan Pendidikan Perguruan Tinggi atas dana Program Kreativitas Mahasiswa (PKM) yang telah diberikan.

\section{DAFTAR PUSTAKA}

Badan Pusat Statistik Provinsi Riau. 2015. Riau Dalam Angka 2015. Pekanbaru: Badan Pusat Statistik Riau.

Balitbang Kemenkes RI. 2013. Riset Kesehatan Dasar; RISKESDAS. Jakarta: Balitbang Kemenkes RI.

Hidayat, A. A. 2009. Pengantar Ilmu Kesehatan Anak. Jakarta: Selemba Medika.

Hruby, A., \& F. B. Hu. 2015. The Epidemiology of Obesity: A Big Picture. Pharmacoeconomics 33(7): 673-689.

Ikatan Dokter Anak Indonesia. 2014. Diagnosis, Tata Laksana, dan Pencegahan Obesitas pada Anak dan Remaja. Jakarta: IDAI.

Ip P, F. K. Ho, L. H. Louie, T. W. Chung, Y. F. Cheung, S. L. Lee, S. S. Hui, W. K. Ho, W. H. Wong, \& F. Jiang. 2017. Childhood Obesity and Physical Activity-Friendly School Environments. Pediatr 191: 110-116.

Kementerian Kesehatan Republik Indonesia. 2012. Pedoman Pencegahan dan Penanggulangan Kegemukan dan Obesitas pada Anak Sekolah. Jakarta: Kemenkes.

Kim, S. H., F. Abbasi, C. Lamendola, A. Liu, D. Ariel, P. Schaaf, K. Grove, V. Tomasso, H. Ochoa, Y. V. Liu, Y. D. Chen, and G. Reaven. 2013. Benefits of liraglutide treatment in overweight and obese older individuals with prediabetes. Diabetes Care 36(10): 3276-3282.

Soegih, \& Wiramihardja. 2009. Tren Obesitas Dulu, Sekarang dan Yang Akan Datang. Dalam: Soegih R. Rachmad dan Wiramihardja, Kunkun K. (Editor). Obesitas Permasalahan dan Terpai Praktis. Jakarta: Sagung Seto, 1-7.

Sutriyanto, E. 2011. Anak Kurang Gizi Karena Pengetahuan Orang Tua Minim.

http://www.tribunnews.com/kesehatan/2011/11/29/anak-kurang-gizi-karena-pengetahuan-orangtua-minim. Diakses pada 29 November 2018. 